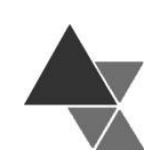

\title{
Modos de organização e desafios da participação dos Agricultores Familiares no Programa Nacional de Alimentação Escolar
}

\author{
Ana Paula Cantarino Frasão do Carmo ${ }^{1}$, Betzabeth Slater Villar ${ }^{2}$, Daniela Bicalho ${ }^{3}$, \\ Flavia da Silva Miguel $^{4}$, Flavia Schwartzman ${ }^{5}$ e Rosana Maria Nogueira ${ }^{6}$
}

Introdução: A venda dos produtos da agricultura familiar para o Programa Nacional de Alimentação Escolar (PNAE) representa uma experiência que favorece a sustentabilidade alimentar. Objetivo: Descrever os alimentos fornecidos ao PNAE e caracterizar a venda do agricultor familiar segundo organização produtiva, considerando estabelecimento familiar e apoio institucional e técnico, nos municípios do estado de São Paulo. Métodos: Tratase de um estudo transversal realizado entre 2012 e 2013 com 110 agricultores que forneceram alimentos para 16 municípios do PNAE no Estado de São Paulo. Os dados foram coletados por meio de questionários estruturados e para a análise foram utilizadas estatística descritiva e teste de McNemar. Resultados: Houve prevalência no fornecimento de alimentos in natura pelos agricultores familiares; e aumento das vendas para mercados institucionais, após a vigência da Lei no 11.947/2009. A falta de apoio institucional e de assistência técnica foram as dificuldades mais prevalentes para os agricultores. Conclusão: A agricultura familiar é uma fonte de acesso a alimentos in natura para o PNAE contribuindo para um cardápio escolar saudável, com alimentos frescos e locais. Os fatores que mais dificultam a venda da agricultura familiar para o PNAE são a necessidade de apoio técnico e institucional.

Palavras-chave: Agricultura familiar; Programa Nacional de Alimentação Escolar; Vendas locais.

\section{Modes of organization and challenges for the participation of family farmers in the National School Feeding Program}

Introduction: Products sale by family farming to the National School Feeding Program (PNAE) represents an experience that favors the sustainability. Objective: To describe food supplied to PNAE and to characterize the family farming sale according to the productive organization, considering family establishment and institutional

${ }^{1}$ Faculdade de Saúde Pública da Universidade de São Paulo. Nutricionista graduada pela Universidade Federal Fluminense. Mestre em Ciências pela Faculdade de Saúde de Pública da Universidade de São Paulo. https://orcid.org/0000-0002-3136-6510- Endereço para correspondência: Faculdade de Saúde Pública. Universidade de São Paulo. Av. Doutor Arnaldo no 715, Cerqueira César, São Paulo, SP. Tel.: +55(11)3061-7853. E-mail:ana_cantarino@yahoo.com.br

${ }^{2}$ Faculdade de Saúde Pública da Universidade de São Paulo. Nutricionista graduada pela Universidade Nacional Mayor de San Marcos. Mestre em Ciências, Doutora e Professora Livre Docente pela Faculdade de Saúde Pública da Universidade de São Paulo. https://orcid.org/0000-0003-2511-1770

${ }^{3}$ Faculdade de Saúde Pública da Universidade de São Paulo. Nutricionista graduada pelo Centro Universitário São Camilo. Mestre e Doutoranda em Ciências pela Faculdade de Saúde de Pública da Universidade de São Paulo. https://orcid.org/0000-0003-4484-6975

${ }^{4}$ Faculdade de Saúde de Pública da Universidade de São Paulo. Nutricionista graduada pela Faculdade de Saúde Pública da Universidade de São Paulo. https://orcid.org/0000-0001-8864-0587

${ }^{5}$ Organização das Nações Unidas para Alimentação e Agricultura. Nutricionista graduada pela Faculdade de Saúde Pública da Universidade de São Paulo. Mestre em Ciências pela Universidade Federal de São Paulo e Doutora em Ciências pela Faculdade de Saúde Pública da Universidade de São Paulo. https://orcid.org/0000-0001-9467-9226

${ }^{6}$ Faculdade de Saúde Pública da Universidade de São Paulo. Nutricionista graduada pela Pontifícia Universidade Católica de Campinas, Mestre em Educação pela Universidade Estadual de Campinas, Doutora em Alimentos e Nutrição pela Universidade Estadual de Campinas, e Pós-doutoranda pela Faculdade de Saúde Pública da Universidade de São Paulo. https://orcid.org/0000-0001-6823-5031 
and technical support, in São Paulo state municipalities. Methods: This is a cross-sectional study conducted with 110 farmers who supplied food to 16 PNAE municipalities in São Paulo state, between 2012 and 2013. Quantitative data was collected through structured questionnaires; and for the analysis, descriptive statistics and McNemar's test were used. Results: There was a prevalence of in natura food supplied by family farmers; and increased sales to institutional markets, after the act 11.947/2009. The lack of institutional support, and the absence of technical assistance were the most prevalent difficulties of the family farmers. Conclusion: Family farming is an access source of in natura food to PNAE contributing to a heathy school menu, with fresh and local food. The factors that make family farming sale to PNAE more difficult are the need for technical and institutional support.

Keywords: Family farming, National School Feeding Program, local sales.

Submetido em: $16 / 04 / 2020$

Aceito em: 10/11/2020

\section{INTRODUÇÃO}

O Programa Nacional de Alimentação Escolar (PNAE) é considerado um dos maiores programas de alimentação escolar do mundo. Apresenta cobertura universal e gratuidade na oferta de suas refeições, sendo apreciado, portanto, como uma importante estratégia de Segurança Alimentar e Nutricional (SAN) ${ }^{[1]}$.

Foi criado em 1954, com denominação de "Campanha da Merenda Escolar". Inicialmente, o propósito, a gestão e a aquisição de gêneros alimentícios do PNAE por meio de licitação pública, eram centralizados e distribuídos para todo o território nacional[2,3]. A partir de 1994, o PNAE passou por um processo de descentralização dos recursos e contou com maior participação da sociedade civil no seu gerenciamento, sendo possível a elaboração de cardápios e a aquisição de gêneros no nível local[3].

A partir de singulares discussões sobre políticas de SAN e a atuação do Programa Fome Zero em 2003, o PNAE foi revisado, consequentemente aumentando os recursos federais alocados e a abrangência do público atendido[ ${ }^{[1]}$. A Resolução no 32 de 10 de agosto de 2006 do Conselho Deliberativo (CD) do Fundo Nacional de Desenvolvimento da Educação (FNDE) prontamente promulgou, entre suas diretrizes, o apoio ao desenvolvimento sustentável, à promoção da alimentação saudável e adequada e à educação alimentar e nutricional[4,5].

Em 2009, o PNAE se somou a uma experiência de compras públicas da agricultura familiar, o Programa de Aquisição de Alimentos (PAA). Passou a contar, dessa forma, com a obrigatoriedade de compra de produtos da agricultura familiar utilizando no mínimo 30\% dos recursos financeiros do FNDE destinados ao PNAE do município, estados e Distrito Federal, ampliando dessa forma, as exigências alimentares e nutricionais relativas à alimentação servida nas escolas públicas ${ }^{[3,6,7]}$.

A Lei 11.947/2009, na qual são apresentados os princípios e diretrizes do Programa, não foi responsável apenas pela obrigatoriedade dos $30 \%$ da compra da Agricultura Familiar (AF) para o PNAE, mas também fortaleceu a intersetorialidade ${ }^{[8]}, \mathrm{O}$ desenvolvimento econômico e sustentável das comunidades ${ }^{[9,10]}$; e auxiliou na redução da desigualdade social, da pobreza e da migração campo-cidadel[1,12], por meio da redistribuição de renda aos agricultores familiares; contribuindo, dessa forma, para a promoção da SAN e soberania alimentar. Além disto, a exemplo do PAA, o PNAE passou também a incentivar a compra de produtos agroecológicos e orgânicos.

É interessante destacar que experiências que exploram a sustentabilidade alimentar vêm sendo desenvolvidas em outros países, como no caso do Reino Unido, no qual escolas primárias e secundárias buscaram adquirir alimentos orgânicos e menos processados industrialmente para suprir as refeições escolares, reduzindo a quantidade de embalagens e aumentando o padrão nutricional dos alimentos. Como resultado, foram adquiridos $90 \%$ de alimentos processados ou frescos - de origem local, reduzindo o custo em transportes e embalagens - e 30\% de 
orgânicos, que reduziram o uso de pesticidas e outros insumos agrícolas ${ }^{[13]}$.

No Brasil, estudo realizado na região Sul mostrou que a Lei 11.947/2009 promoveu modificação no nível do consumo, no que diz respeito à aceitação de alimentos mais saudáveis e adequados por parte dos alunos $[3,14]$.

Embora o processo de compra da agricultura familiar para o PNAE tenha sido precedido da experiência de dispensa de licitação do PAA, cabe ressaltar que não foi fácil a aceitação da compra sem a licitação. Foi necessário vencer dificuldades, como por exemplo, o lobby dos fornecedores de alimentação escolar ${ }^{[15]}$.

Entre as maiores dificuldades observadas para a aplicação da Lei, está a pouca organização dos produtores familiares para fazer frente à nova demanda, o que inclui, entre outras coisas, a dificuldade na emissão de nota fiscal e o despreparo para atender às exigências sanitárias e de regularidade de fornecimento. Logo, mesmo com os avanços promovidos pela experiência prévia do PAA, a agricultura familiar não estava estruturada suficientemente ainda para fornecer para o PNAE na escala e qualidade exigidas com a nova lei. Além disso, havia a dificuldade de logística: nem os agricultores conseguiam muitas vezes entregar, nem a escola ou a prefeitura possuía um centro para receber os produtos $[1,4,10,15,16,17]$.

Por ora, poucos estudos abordaram a venda da agricultura familiar para o PNAE. O presente trabalho propõe descrever os alimentos fornecidos ao Programa de Alimentação Escolar e caracterizar a venda do agricultor familiar segundo organização produtiva, considerando estabelecimento familiar e apoio institucional e técnico, nos municípios do estado de São Paulo.

\section{MÉTODOS}

Este estudo faz parte do projeto intitulado “ $\mathrm{O}$ encontro entre o Programa Nacional de Alimentação Escolar (PNAE) e a agricultura familiar: avaliação do processo de implementação e dos possíveis efeitos das compras locais, segundo a Lei 11.947/2009", que tem por objetivo identificar as condições e os fatores envolvidos no processo de implementação da compra da agricultura familiar pelo PNAE e os possíveis efeitos desta vinculação na alimentação oferecida nas escolas e na agricultura familiar.

Trata-se de um estudo transversal que envolve métodos de análise quantitativa. O local de estudo foi o estado de São Paulo, localizado na região sudeste do Brasil. As unidades de análise foram os 16 municípios do estado de São Paulo selecionados no projeto principal, por comprarem alimentos de agricultores familiares individuais, associações e/ou cooperativas do mesmo município e, eventualmente, também de outros municípios para o PNAE. Foram estudados 16 municípios: Capivari, Floreal, Itatinga, Júlio Mesquita, Lucélia, Maracaí, Mococa, Monteiro Lobato, Orindiúva, Ouro Verde, Populina, Registro, Sagres, Sete Barras, Tabapuã e Uchoa.

A coleta dos dados primários foi realizada em 2013, por nutricionistas e estudantes de nutrição previamente treinados, por meio de dois questionários estruturados. O primeiro, aplicado com os nutricionistas responsáveis técnicos do PNAE para identificar os municípios que compraram diretamente da agricultura familiar em 2012. O segundo questionário foi aplicado com os agricultores familiares que venderam para o PNAE em 2012, individualmente ou por meio de associação ou cooperativa. O critério de inclusão foi residir no município que comprou da agricultura familiar para abastecer o PNAE, ou seja, não foram incluídos no estudo agricultores de fora que vendiam para o município, mesmo que por meio de uma associação/cooperativa do mesmo município. Os questionários foram respondidos por correio eletrônico, ligação telefônica ou entrevista presencial.

As análises estatísticas foram realizadas utilizando o Software Data Analysis and Statistical - Stata ${ }^{\circledR}$ versão 12.0. O programa estatístico está licenciado para o uso nos equipamentos dos laboratórios de informática da Faculdade de Saúde Pública da Universidade de São Paulo. Na análise descritiva foram calculadas frequências absolutas e medidas de tendência central e dispersão (média e valores mínimos e máximos). O teste de Mc Nemar foi utilizado para verificar diferenças entre a comercialização antes e depois da Lei Federal 11.947/2009.

Para garantir a precisão dos dados, após as entrevistas, todos os questionários passaram por dupla revisão, primeiramente pelo pesquisador de campo e, 
em um segundo momento, pela pesquisadora principal, com o objetivo de solucionar possíveis inconsistências. Após a revisão, os dados foram digitados no programa Epidata®.

O estudo foi aprovado pelo Comitê de Ética em Pesquisa, no 54197816.1.0000.5421. As informações foram coletadas para os participantes que assinaram o Termo de Consentimento Livre e Esclarecido, para atender a Resolução 466 de Dezembro de 2012.

\section{RESULTADOS}

\section{Descrição dos alimentos fornecidos pela Agricultura Familiar ao PNAE em 2012}

Os agricultores familiares dos 16 municípios estudados forneceram para o PNAE um total de 69 alimentos (Tabela 1) que em quase sua totalidade foram classificados como in natura segundo a NOVA classificação dos alimentos que categoriza os alimentos de acordo com a extensão e o propósito de seu processamento[18]. Como exemplo temos as frutas: mamão ${ }^{1}$, $\operatorname{coco}^{2}$, abacate ${ }^{3}$, manga ${ }^{4}$, limão ${ }^{5}$, acerola ${ }^{6}$, jabuticaba ${ }^{7}$, tangerina ${ }^{8}$, morango ${ }^{9}$, caqui ${ }^{10}$, melancia ${ }^{11}$, goiaba $^{12}$, laranja ${ }^{13}$, ponkan ${ }^{14}$, banana ${ }^{15}$, maracuja ${ }^{16}$, abacate $^{17}$, carambola ${ }^{18}$, jaca ${ }^{19}$, maná20, mexerica ${ }^{21}$. E os legumes e verduras: pepino ${ }^{22}$, berinjela ${ }^{23}$, cebolinha ${ }^{24}$, repolho ${ }^{25}$, acelga ${ }^{26}$, coentro ${ }^{27}$, rabanete ${ }^{28}$, hortelã ${ }^{29}$, espinafre ${ }^{30}$, batata doce ${ }^{31}$, salsa ${ }^{32}$, quiabo ${ }^{33}$, pimentão $^{34}$, vagem $^{35}$, jilós ${ }^{36}$, chuchu ${ }^{37}$, alface ${ }^{38}$, almeirão ${ }^{39}$, cheiro verde $^{40}$, cenoura ${ }^{41}$, beterraba ${ }^{42}$, milho ${ }^{43}$, abóbora ${ }^{44}$, abobrinha ${ }^{45}$, mandioca ${ }^{46}$, brócolis ${ }^{47}$, couve ${ }^{48}$, tomate ${ }^{49}$, repolho ${ }^{50}$, chicória ${ }^{51}$, rúcula ${ }^{52}$, batata ${ }^{53}$, couve-flor ${ }^{54}$, alho ${ }^{55}$, palmito pupunha ${ }^{56}$, cebola ${ }^{57}$, maxixe $e^{58}$, inhame ${ }^{59}$, escarola ${ }^{60}$, salsinha ${ }^{61}$, tomate cereja ${ }^{62}$, cará ${ }^{63}$.

Foram fornecidos alimentos minimamente processados como: feijão ${ }^{64}$, caféc 65 , leite ${ }^{66}$ e polpas de frutas ${ }^{67}$. Foram encontrados o mel ${ }^{68}$ como integrante do grupo ingredientes culinários e o pão caseiro ${ }^{69}$ como integrante do grupo processado.

Verificou-se uma variação de alimentos fornecidos pelos agricultores familiares ao PNAE. Enquanto agricultores de alguns municípios forneceram uma maior variedade de alimentos, os de outros municípios forneceram uma menor variedade de alimentos ou apenas um alimento, como é o caso do município de Sete Barras que forneceu apenas banana. 
Tabela 1. Descrição dos alimentos da agricultura familiar fornecidos para o PNAE. Municípios do estado de São Paulo, 2012.

\begin{tabular}{|c|c|}
\hline Municípios & Alimentos \\
\hline Capivari & Goiaba, laranja, chuchu, ponkan, alface. \\
\hline Floreal & Alface, almeirão, cheiro verde, cenoura, beterraba, milho, abóbora. \\
\hline Itatinga & $\begin{array}{l}\text { Abobrinha, mel, mandioca, pepino, vagem, brócolis, alface, cenoura, couve, beterraba, laranja, cheiro } \\
\text { verde, banana, tomate, acelga, repolho, chicória, abóbora. }\end{array}$ \\
\hline Júlio Mesquita & $\begin{array}{l}\text { Café, alface, leite, mandioca, abobrinha, rúcula, chicória, maracujá, almeirão, couve, chuchu, cheiro } \\
\text { verde, cenoura, brócolis. }\end{array}$ \\
\hline Lucélia & $\begin{array}{l}\text { Banana, mamão, mandioca, tomate, coco, abobrinha, abacate, manga, beterraba, almeirão, alface, } \\
\text { cenoura, cheiro verde, pepino, rúcula, feijão, ponkan, limão, acerola, maracujá, jabuticaba, berinjela, } \\
\text { laranja, tangerina, cebolinha, cheiro verde, morango, repolho, acelga, brócolis, coentro, rabanete, } \\
\text { hortelã, espinafre, leite, couve, abóbora, batata doce, caqui, salsa, quiabo, pimentão, vagem. }\end{array}$ \\
\hline Maracaí & $\begin{array}{l}\text { Alface, couve, abobrinha, repolho, chuchu, beterraba, brócolis, cheiro verde, cenoura, salsa, cebolinha, } \\
\text { banana, tomate, rúcula, couve, laranja, chicória, chuchu, pimentão, abóbora, pepino, banana, quiabo, } \\
\text { jiló, ponkan, mandioca, mexerica, almeirão, melancia, jabuticaba, manga, pepino, rúcula, mamão. }\end{array}$ \\
\hline Mococa & $\begin{array}{l}\text { Alface, repolho, couve, mel, cheiro verde, tomate cereja, pimentão, batata, cebolinha, banana, beterraba, } \\
\text { cenoura, abobrinha, laranja, mandioca. }\end{array}$ \\
\hline Monteiro Lobato & $\begin{array}{l}\text { Banana, alface, chicória, mel, abobrinha, limão, tomate, cheiro verde, couve, couve flor, brócolis, } \\
\text { repolho, mandioca. }\end{array}$ \\
\hline Orindiúva & $\begin{array}{l}\text { Alface, cenoura, tomate, abobrinha, pepino, repolho, rúcula, almeirão, salsa, cheiro verde, mandioca, } \\
\text { batata, alho, melancia. }\end{array}$ \\
\hline Ouro Verde & $\begin{array}{l}\text { Couve, alface, rúcula, almeirão, chicória, cebolinha, cheiro verde, laranja, manga, mandioca, limão, } \\
\text { maracujá, repolho, vagem, melancia, banana, abóbora, leite, coco, ponkan, polpa de acerola, pão caseiro, } \\
\text { milho, almeirão. }\end{array}$ \\
\hline Populina & Alface, couve manteiga, cheiro verde, rúcula, almeirão, mandioca, brócolis, abobrinha. \\
\hline Registro & $\begin{array}{l}\text { Alface, acelga, cheiro verde, pepino, cebola, cenoura, batata, mandioca, quiabo, banana, abóbora, } \\
\text { chuchu, maxixe, pepino, acelga, couve, salsa, batata doce, abacate, maracujá, inhame, limão, repolho, } \\
\text { beterraba, abobrinha, berinjela, carambola, vagem, jaca, mamão, polpa de maracujá, polpa de goiaba, } \\
\text { maná, jiló, mexerica, palmito pupunha, cará, melancia. }\end{array}$ \\
\hline Sagres & $\begin{array}{l}\text { Abóbora, mandioca, batata, laranja, ponkan, couve, almeirão, rúcula, alface, cheiro verde, vagem, } \\
\text { banana, manga. }\end{array}$ \\
\hline Sete Barras & Banana. \\
\hline Tabapuã & Mandioca, alface, limão, cheiro verde, couve, rúcula. \\
\hline Uchoa & Alface, almeirão, escarola, salsinha, cebolinha, vagem, couve manteiga, abobrinha, mandioca, rúcula. \\
\hline
\end{tabular}




\section{Caracterização da venda do Agricultor Familiar antes e depois da Lei Federal no 11.947/2009}

De acordo com a Tabela 2, os agricultores familiares reduziram suas vendas para as feiras livres, supermercados, centrais de abastecimento, sacolão, atravessadores e atacados e aumentaram suas vendas para o PNAE, PAA e outros mercados (porta em porta, restaurantes e quitanda própria). Um destaque especial pode ser atribuído a uma redução das vendas por meio do atravessador que caiu de 40,9\% para $22,7 \%$ e um aumento nas vendas para o PNAE, PAA e outros mercados de $42,7 \%$ para $56,4 \%$ após a lei.

Tabela 2. Caracterização da venda do agricultor familiar em outros mercados antes e depois da Lei Federal no 11.947/2009. Estado de São Paulo, 2012

\begin{tabular}{|c|c|c|c|c|}
\hline \multirow[t]{2}{*}{ Variáveis } & \multicolumn{4}{|c|}{$\begin{array}{l}\text { Agricultores Familiares } \\
\text { Depois da Lei }\end{array}$} \\
\hline & Antes da Lei & $\underset{\mathrm{n}(\%)}{\operatorname{Sim}}$ & $\begin{array}{l}\text { Não } \\
\text { n (\%) }\end{array}$ & $p^{* *}$ \\
\hline Feira livre & $\begin{array}{l}\text { Sim } \\
\text { Não }\end{array}$ & $\begin{array}{c}23(20,9) \\
2(1,8)\end{array}$ & $\begin{array}{l}16(14,5) \\
69(62,7)\end{array}$ & 0,001 \\
\hline Supermercados & $\begin{array}{l}\text { Sim } \\
\text { Não }\end{array}$ & $\begin{array}{c}34(30,9) \\
3(2,7)\end{array}$ & $\begin{array}{l}15(13,6) \\
58(52,7)\end{array}$ & 0,008 \\
\hline Ceasa & $\begin{array}{l}\text { Sim } \\
\text { Não }\end{array}$ & $\begin{array}{c}10(9,1) \\
0(0,0)\end{array}$ & $\begin{array}{c}12(0,9) \\
88(88,0)\end{array}$ & $<0,001$ \\
\hline Sacolão & $\begin{array}{l}\text { Sim } \\
\text { Não }\end{array}$ & $\begin{array}{c}27(24,5) \\
3(2,7)\end{array}$ & $\begin{array}{l}12(10,9) \\
68(61,8)\end{array}$ & 0,035 \\
\hline Atravessador & $\begin{array}{l}\text { Sim } \\
\text { Não }\end{array}$ & $\begin{array}{c}22(20,0) \\
3(2,7)\end{array}$ & $\begin{array}{l}23(20,9) \\
62(56,4)\end{array}$ & $<0,001$ \\
\hline Atacado & $\begin{array}{l}\text { Sim } \\
\text { Não }\end{array}$ & $\begin{array}{c}18(16,4) \\
1(9,0)\end{array}$ & $\begin{array}{c}5(4,5) \\
91(82,7)\end{array}$ & 0,219 \\
\hline PNAE, PAA e outros mercados* & $\begin{array}{l}\text { Sim } \\
\text { Não }\end{array}$ & $\begin{array}{l}44(40,0) \\
18(16,4)\end{array}$ & $\begin{array}{c}3(2,7) \\
45(40,9)\end{array}$ & 0,002 \\
\hline
\end{tabular}

Fonte: Autores

Nota: $\mathrm{n}=20$

* Programa de Aquisição de Alimentos, Programa Nacional de Alimentação Escolar, porta em porta, restaurantes e quitanda própria.

** Teste de Mc Nemar

A Tabela 3 caracteriza o estabelecimento familiar segundo organização produtiva. De modo geral, os agricultores são proprietários da sua terra e não contratam mão de obra para a lavoura, em destaque os cooperados com $86,2 \%$. Os dados revelam que $77,3 \%$ dos agricultores individuais e $79,3 \%$ dos cooperados tiraram a Declaração de Aptidão ao Programa Nacional de Fortalecimento da Agricultura Familiar (DAP) apenas depois da Lei Federal no 11.947/2009 e 61\% dos agricultores associados já haviam obtido antes da Lei. O motivo para a maior parte dos agricultores cooperados $(72,4 \%)$ e associados $(79,7 \%)$ obter a DAP foi o acesso ao Programa Nacional de Fortalecimento da Agricultura Familiar (PRONAF), já entre os agricultores individuais, o principal motivo foi o acesso ao PNAE. 
Tabela 3. Caracterização do estabelecimento familiar segundo organização produtiva. Estado de São Paulo, 2012

\begin{tabular}{|c|c|c|c|c|c|c|}
\hline \multirow{3}{*}{ Variáveis } & \multicolumn{6}{|c|}{ Organização Produtiva } \\
\hline & \multicolumn{2}{|c|}{ Individual } & \multicolumn{2}{|c|}{ Cooperado } & \multicolumn{2}{|c|}{ Associado } \\
\hline & $\mathrm{n}=22$ & $(\%)$ & $n=29$ & $(\%)$ & $\mathrm{n}=59$ & $(\%)$ \\
\hline \multicolumn{7}{|c|}{ Local de produção é assentamento de reforma agrária } \\
\hline $\operatorname{Sim} T-10$ & 1 & $(4,5)$ & 3 & $(10,3)$ & 2 & $(3,4)$ \\
\hline Não & 21 & $(95,5)$ & 26 & $(89,7)$ & 57 & $(96,6)$ \\
\hline \multicolumn{7}{|l|}{ Agricultor é proprietário da terra } \\
\hline Sim & 12 & $(54,5)$ & 25 & $(86,2)$ & 42 & $(71,2)$ \\
\hline Não & 10 & $(45,5)$ & 4 & $(13,8)$ & 17 & $(28,8)$ \\
\hline \multicolumn{7}{|l|}{ Agricultor contrata mão de obra } \\
\hline $\operatorname{Sim}$ & 10 & $(45,5)$ & 4 & $(13,8)$ & 22 & $(37,3)$ \\
\hline Não & 12 & $(54,5)$ & 25 & $(86,2)$ & 37 & $(62,7)$ \\
\hline \multicolumn{7}{|l|}{ Ano que tirou a DAP } \\
\hline Antes da Lei no 11.947/09 & 5 & $(22,7)$ & 6 & $(20,7)$ & 36 & $(61,0)$ \\
\hline Depois da Lei oo 11.947/09 & 17 & $(77,3)$ & 23 & $(79,3)$ & 23 & $(39,0)$ \\
\hline \multicolumn{7}{|l|}{ Motivo que o levou a tirar a DAP } \\
\hline Acesso ao PRONAF & 10 & $(45,5)$ & 21 & $(72,4)$ & 47 & $(79,7)$ \\
\hline Acesso ao PAA & 1 & $(4,5)$ & 3 & $(10,3)$ & 2 & $(3,40)$ \\
\hline Acesso ao PNAE & 11 & $(50,0)$ & 5 & $(17,3)$ & 10 & $(16,9)$ \\
\hline
\end{tabular}

Nota:

DAP - Declaração de Aptidão ao Programa Nacional de Fortalecimento da Agricultura

PRONAF - Programa Nacional de Fortalecimento da Agricultura Familiar

PAA - Programa de Aquisição de Alimentos

PNAE - Programa Nacional de Alimentação Escolar

A Tabela4 apresenta os dados do apoio institucional e técnico segundo organização produtiva. Quase a totalidade $(95,5 \%)$ dos agricultores conhecem a Lei Federal n ${ }^{\circ} 11.947 / 2009$. No entanto, 59,1\% dos agricultores individuais nunca participaram de algum evento ou palestra sobre a mesma.

A maioria dos agricultores cooperados $(65,5 \%)$ e Associados $(71,2 \%)$ não foi contatado pelo nutricionista do município antes do início da venda para a identificação dos alimentos produzidos. Houve ausência de apoio do nutricionista do município durante o processo de venda ao PNAE em quase metade dos produtores individuais $(45,5 \%)$ e na maioria dos cooperados $(82,8 \%)$ e dos associados $(67,8 \%)$. 
Tabela 4. Caracterização do apoio institucional e técnico segundo organização produtiva. Estado de São Paulo, 2012

\begin{tabular}{|c|c|c|c|c|c|c|}
\hline \multirow{3}{*}{ Variáveis } & \multicolumn{6}{|c|}{ Organização Produtiva } \\
\hline & \multicolumn{2}{|c|}{ Individual } & \multicolumn{2}{|c|}{ Cooperado } & \multicolumn{2}{|c|}{ Associado } \\
\hline & $\mathrm{n}=22$ & $(\%)$ & $\mathrm{n}=29$ & $(\%)$ & $\mathrm{n}=59$ & $(\%)$ \\
\hline \multicolumn{7}{|c|}{ O agricultor conhece a Lei no 11.947/09 } \\
\hline Sim & 22 & $(100,0)$ & 27 & $(93,1)$ & 56 & $(94,9)$ \\
\hline Não & 0 & $(0,0)$ & 2 & $(6,9)$ & 3 & $(5,1)$ \\
\hline \multicolumn{7}{|c|}{$\begin{array}{l}\text { O agricultor assistiu a algum evento sobre a Lei no } \\
11.947 / 09\end{array}$} \\
\hline Sim & 9 & $(40,9)$ & 24 & $(82,8)$ & 44 & $(74,6)$ \\
\hline Não & 13 & $(59,1)$ & 5 & $(17,2)$ & 15 & $(25,4)$ \\
\hline \multicolumn{7}{|c|}{ Nutricionista fez contato com o agricultor } \\
\hline Sim & 13 & $(59,0)$ & 10 & $(34,5)$ & 17 & $(28,8)$ \\
\hline Não & 9 & $(41,0)$ & 19 & $(65,5)$ & 42 & $(71,2)$ \\
\hline \multicolumn{7}{|l|}{ Agricultor teve apoio da nutricionista } \\
\hline Sim & 12 & $(54,5)$ & 5 & $(17,2)$ & 19 & $(32,2)$ \\
\hline Não & 10 & $(45,5)$ & 24 & $(82,8)$ & 40 & $(67,8)$ \\
\hline \multicolumn{7}{|c|}{ Agricultor teve apoio de órgão da Agricultura Familiar } \\
\hline Sim 1 & 14 & $(63,3)$ & 4 & $(13,8)$ & 41 & $(69,5)$ \\
\hline Não & 8 & $(36,4)$ & 25 & $(86,2)$ & 18 & $(30,5)$ \\
\hline
\end{tabular}

A Tabela 5 caracteriza a venda da AF para o PNAE, segundo organização produtiva. Mais da metade dos agricultores cooperados $(55,2 \%)$ e associados $(50,8 \%)$ vendia para o PAA antes da Lei $n^{\circ}$ $11.947 / 2009$, enquanto $86,4 \%$ dos individuais não vendiam para o PAA. Cerca de $90 \%$ dos agricultores iniciaram a venda para o PNAE após a promulgação da Lei Federal, e 81,8\% dos individuais, $89,7 \%$ dos cooperados e $83,1 \%$ dos associados seguem a legislação sanitária no fornecimento da produção. Quanto à forma de entrega dos alimentos produzidos, $86,4 \%$ dos agricultores individuais julgam não ser conveniente para os mesmos. Os agricultores relataram fatores que dificultam a venda para o PNAE e de modo geral, falta de apoio institucional e assistência técnica foi a dificuldade mais marcante para os agricultores. Em relação às sugestões apontadas pelos agricultores que poderiam facilitar a venda para o PNAE, os individuais e associados em maioria, relataram a necessidade de apoio comercial e os cooperados $(44,8 \%)$ alegaram a necessidade de mais organização e planejamento. 
Tabela 5. Caracterização da venda da AF para o PNAE segundo organização produtiva. Estado de São Paulo, 2012

\begin{tabular}{|c|c|c|c|c|c|c|}
\hline \multirow{3}{*}{ Variáveis } & \multicolumn{6}{|c|}{ Organização Produtiva } \\
\hline & \multicolumn{2}{|c|}{ Individual } & \multicolumn{2}{|c|}{ Cooperado } & \multicolumn{2}{|c|}{ Associado } \\
\hline & $\mathrm{n}=22$ & $(\%)$ & $\mathrm{n}=29$ & $(\%)$ & $\mathrm{n}=59$ & $(\%)$ \\
\hline \multicolumn{7}{|l|}{$\begin{array}{l}\text { O agricultor vendia para o PAA antes da Lei no } \\
11.947 / 09\end{array}$} \\
\hline $\operatorname{Sim}$ & 3 & $(13,6)$ & 16 & $(55,2)$ & 30 & $(50,8)$ \\
\hline Não & 19 & $(86,4)$ & 13 & $(44,8)$ & 29 & $(49,2)$ \\
\hline \multicolumn{7}{|l|}{ Quando começou a vender para o PNAE } \\
\hline Antes da Lei no 11.947/09 & 2 & $(9,1)$ & 3 & $(10,3)$ & 5 & $(8,5)$ \\
\hline Depois da Lei no 11.947/09 & 20 & $(90,9)$ & 26 & $(89,7)$ & 54 & $(91,5)$ \\
\hline \multicolumn{7}{|l|}{ O agricultor segue a legislação sanitária } \\
\hline $\operatorname{Sim}$ & 18 & $(81,8)$ & 26 & $(89,7)$ & 49 & $(83,1)$ \\
\hline Não & 4 & $(18,2)$ & 3 & $(10,3)$ & 10 & $(16,9)$ \\
\hline \multicolumn{7}{|l|}{ Forma de entrega é boa } \\
\hline Sim & 3 & $(13,6)$ & 21 & $(72,4)$ & 51 & $(86,4)$ \\
\hline Não & 19 & $(86,4)$ & 8 & $(27,6)$ & 8 & $(13,6)$ \\
\hline \multicolumn{7}{|l|}{ Dificuldades para a venda } \\
\hline Nenhuma & 6 & $(27,3)$ & 5 & $(17,2)$ & 26 & $(44,1)$ \\
\hline Burocracia & 3 & $(13,6)$ & 10 & $(34,5)$ & 12 & $(20,3)$ \\
\hline Falta de apoio institucional e assistência técnica & 10 & $(45,5)$ & 11 & $(38,0)$ & 15 & $(25,4)$ \\
\hline Exigências do PNAE & 2 & $(9,1)$ & 3 & $(10,3)$ & 2 & $(3,4)$ \\
\hline Lucro baixo & 1 & $(4,5)$ & 0 & $(0,0)$ & 4 & $(6,8)$ \\
\hline \multicolumn{7}{|l|}{ Sugestões para a venda } \\
\hline Nenhuma & 1 & $(4,5)$ & 2 & $(6,9)$ & 0 & $(0,0)$ \\
\hline Apoio comercial & 12 & $(54,6)$ & 8 & $(27,6)$ & 31 & $(52,5)$ \\
\hline Organização e Planejamento & 6 & $(27,3)$ & 13 & $(44,8)$ & 27 & $(45,8)$ \\
\hline Apoio institucional & 3 & $(13,6)$ & 6 & $(20,7)$ & 1 & $(1,7)$ \\
\hline
\end{tabular}

\section{DISCUSSÃO}

O presente estudo caracterizou os alimentos fornecidos pela agricultura familiar como in natura em quase sua totalidade. Pôde-se observar uma grande variedade de frutas, verduras e legumes fornecidos por esses agricultores no período estudado. O potencial de produção da agricultura familiar para alimentos frescos e da estação é considerável e importante, sendo essencial para compor o cardápio dos escolares, e proporcionando uma alimentação saudável[19], pautada no guia alimentar para a população brasileira [20] e nas diretrizes do PNAE[6,21].

O Programa dessa forma é considerado uma política pública de proteção social para essas famílias.
Isso devido a Lei Federal no 11.947/2009 estabelecer a obrigatoriedade de investimento de $30 \%$ dos recursos federais destinados ao PNAE, nos municípios, da compra de alimentos diretamente da agricultura familiar[6]. Iniciativas como essas, de compras institucionais da agricultura familiar, configuram-se como importante estratégia de segurança alimentar e nutricional, de cumprimento do direito humano à alimentação adequada e de promoção do desenvolvimento sustentável a longo prazo[22]. Ao mesmo tempo, as familias agricultoras garantem renda para desenvolver seus estabelecimentos e alimentos para sua sobrevivência. Assim, o PNAE se torna um mercado institucional garantido e protege um pequeno grupo de produtores locais de um sistema agrícola voltado para o agronegócio. 
Questões socioeconômicas estão intrinsecamente ligadas à oferta e a produção de alimentos. Oliveira, Sambuichi \& Silva (2013)[23] relataram em seu estudo, a existência de um alto percentual de produtores diversificados, que atuam na policultura no Sul do Brasil. Segundo os autores, nessa região, estão os agricultores familiares mais produtivos e organizados, entre as possíveis explicações para isso, temos a tradição camponesa voltada para o plantio em policultura e o maior percentual de cooperativismo/associativismo existente entre os produtores. Outro fato, é que na mesma região, encontram-se também os maiores percentuais de produtores orgânicos e agroecológicos, o que é mais um fator que estimula a produção diversificada, atendendo ao mercado do PNAE.

Os resultados mostraram que a comercialização dos agricultores se modificou com a Lei no 11.947/2009. Após a promulgação da lei, os agricultores passaram a comercializar menos com os atravessadores, centrais de abastecimento, atacados, supermercados e passaram a comercializar mais com outros mercados institucionais, como o PAA e o PNAE. Nota-se a partir desse momento a importância da Lei no 11.947/2009 e a importância de políticas públicas que protejam os agricultores familiares, para que possam contar com um mercado institucional e com a venda direta garantida. Pode-se dizer que não é apenas a garantia de venda, mas, comercialização e continuidade do estabelecimento familiar ${ }^{[22]}$.

Para Dias et al. (2013)[24], apesar dos investimentos na agricultura familiar, a prática da comercialização tem se apresentado sempre como um dos principais dilemas para os agricultores familiares, os quais muitas vezes se tornam vulneráveis à ação dos chamados "atravessadores" ou intermediários que compram os seus excedentes de produção agrícola por baixo preço e vendem por um preço bem maior nos mercados.

A compra direta de produtos da agricultura familiar no PNAE, diminuindo a intermediação, pode contribuir para aumento expressivo da remuneração dos agricultores, atingindo um dos objetivos do programa que é o de melhorar suas condições de vida[25].

A caracterização do estabelecimento familiar foi importante para descrever semelhanças existentes entre os três diferentes grupos de agricultores familiares (individuais, cooperados e associados). No quesito local de produção da terra, os três grupos de agricultores em sua maioria eram proprietários de suas terras (não detentores de assentamentos de reforma agrária) e não contratavam mão de obra para a lavoura.

Outrora, com relação ao ano em que os agricultores obtiveram a DAP e ao motivo pelo qual tiraram a DAP, apresentaram diferenças entres os grupos. Os agricultores individuais e os cooperados tiraram a DAP depois da Lei no 11.947/2009 e os associados antes. Com relação ao motivo que os levou a tirar a DAP, os individuais responderam que foi o acesso ao PNAE, e os cooperados e associados o acesso ao PRONAF.

Segundo estudo de Tesche \& Machado (2012)[26], as redes de cooperação formadas entre produtores, geradas a partir de relações de trabalho e das relações sociais de reciprocidade desempenham um papel importante na formação de confiança entre os agricultores. Essas redes de cooperação proporcionaram melhores resultados nos indicadores sociais e econômicos. Observaram que um maior número de famílias do grupo dos cooperados foi beneficiado pelas políticas públicas dirigidas ao desenvolvimento rural, sendo que $81,2 \%$ das familias do grupo cooperados acessaram o Programa de Manejo dos Recursos Naturais e de Combate à Pobreza sobre os agricultores familiares assistidos, conhecido como RS RURAL e $100 \%$ o PRONAF investimento, ao passo que apenas $37,5 \%$ das famílias do grupo individual acessaram o RS RURAL e 87,5 o PRONAF.

No âmbito do apoio institucional e técnico percebe-se que os agricultores conheciam a Lei no $11.947 / 2009$. No entanto, apresentaram diferenças a respeito de alguns aspectos como: se assistiram a algum evento sobre a Lei no $11.947 / 2009$, em relação ao contato da nutricionista com o agricultor, ao apoio da nutricionista para vender ao PNAE e ao apoio de órgão da AF. Segundo trabalho de Costa et al. (2015) ${ }^{[27]}$ no que diz respeito à assistência técnica, apenas $7 \%$ das cooperativas não são assessoradas. O restante (93\%) é assessorado de alguma forma. Dentre as organizações que prestam assessoria, destaca-se a Empresa de Assistência Técnica e Extensão Rural (EMATER), presente em 39\% das cooperativas, seguida pelas ONG em $18 \%$, e o restante $(36 \%)$ é assistido por universidades, Serviço Brasileiro de Apoio às Micro e 
Pequenas Empresas (Sebrae), instituições privadas e outros tipos de organização de apoio e fomento. No que se refere à assistência técnica, a grande parte é feita sob aspectos produtivos e assessoria individualizada na propriedade do cooperado.

Os resultados da caracterização da venda da agricultura familiar para o PNAE segundo organização produtiva revelam, como aspectos comuns, que os agricultores começaram a vender para o PNAE após a Lei no 11.947/2009, e seguem a legislação sanitária no fornecimento da produção. Como fatores que dificultam a venda para o PNAE, a falta de apoio institucional e assistência técnica foram notáveis. Costa et al. (2015) ${ }^{[27]}$ destacam a importância das políticas de assistência técnica e extensão rural de acompanhamento sistemático e contínuo.

Segundo Souza (2012)[28] a presença de um grande número de produtores que não se encontra organizado em associações ou cooperativas também é um fator que tem restringido suas participações no Programa. No caso estudado, para a região do Vale do Ribeira no estado de São Paulo, a desconfiança dos produtores em relação ao associativismo e, portanto, a resistência a se vincularem a essas organizações foi uma das dificuldades apontadas por produtores e gestores para que se avançasse na execução do PNAE.

Estudo de Alexandre (2016) ${ }^{[29]}$ considera a organização dos produtores em cooperativas uma ação fundamental para a efetivação da compra pelo PNAE. Percebe-se que a organização dos agricultores, mesmo que em associações ou em grupos não formalizados, agregam maior poder de negociação, promove a redução nos custos de logística e consequentemente tornam estes mais competitivos no mercado devido ao maior volume de produção ofertado. Os agricultores organizados tendem ainda a procurar diversificação de mercados, incluindo nestes os institucionais ${ }^{[30] .}$

No entanto, inúmeros são os desafios das organizações locais, sendo comum cooperativas que foram constituídas com o único objetivo de facilitar a comercialização. Algumas cooperativas não possuem identidade, as direções são centralizadas em poucos líderes e há muitos problemas de gestão administrativa e de recursos, além de questões voltadas para assistência técnica e adequação sanitária|[27].
Uma solução encontrada para uma cooperativa foi o estabelecimento de parceria com a Universidade Federal de Goiás para a execução de uma ação de extensão em 2013. Na execução, os técnicos e estudantes atuam junto à cooperativa nas ações de organização da produção dos agricultores, passando pela gestão e chegando até a comercialização de seus produtos com abertura e garantia de diversos mercados ${ }^{[31]}$.

Segundo Triches \& Schneider (2012) ${ }^{[32]}$, o gerenciamento, a distribuição e a venda exigem organização para garantir a autonomia dos agricultores. Essa organização nem sempre é formalizada, mas gerada a partir de estratégias às vezes consideradas ilegais. Nesse sentido, os autores afirmam que a organização local favorece ou não os produtores, dependendo do apoio dos órgãos representativos como EMATER e Sindicado dos Trabalhadores Rurais, e do poder público.

Para Belivaqua \& Triches (2014)[33], é importante entender a organização dos agricultores familiares como processo, ou seja, considerar que dentro das organizações produtivas (Associações ou Cooperativas), os agricultores passam por inúmeras dificuldades e obstáculos, entender como esses agricultores lidam com essas implicações é muito importante. É preciso considerar que independente da forma que os agricultores estão organizados, as dificuldades existem e devem ser rompidas por mecanismos de construção e efetivação das políticas voltadas para a agricultura familiar.

As formas de organização produtivas (agricultores individuais, cooperados e associados) trazem consigo as características e modelos de produção rural que existem há muitos anos. A escolha de como melhor trabalhar é única e exclusiva do agricultor, a ele deve ser dado o direito de como melhor se organizar.

O importante é conhecer as formas de organização e respeitá-las tentando adaptá-las às exigências e padrões do PNAE, capacitando os agricultores de como melhor aproveitar as oportunidades que lhes são dadas dentro das legislações. Dado isso, vislumbra-se a assistência técnica e rural que deve ser oferecida aos agricultores familiares. 
As sugestões apontadas pelos agricultores que poderiam facilitar a venda para o PNAE, diferiram entre os grupos: os individuais e associados relataram a necessidade de apoio comercial e os cooperados alegaram a necessidade de mais organização e planejamento. Segundo estudo de Gonçalves (2014) ${ }^{[34]}$ é imperativo que as associações e cooperativas deem um passo à frente em direção à profissionalização de suas estruturas organizacionais incorporando em seus quadros profissionais treinados e capacitados tanto para lidar com os detalhes burocráticos das compras públicas, quanto para realizar planos estratégicos que possam levar essas organizações a conquista de melhores posições no mercado. A profissionalização, apesar de demandar investimentos e de aumentar os custos operacionais, tem se mostrado o caminho mais seguro para a melhoria da situação econômica dessas organizações, bem como para suas estruturas organizacionais.

Todas as três formas de organização produtiva apresentadas neste trabalho devem ser respeitadas e estudadas pelos profissionais que diretamente trabalham com as compras públicas para a alimentação escolar, com o intuito de facilitar o processo de compra.

\section{CONCLUSÃO}

Neste estudo, observamos uma maior prevalência do fornecimento de alimentos in natura pelos agricultores familiares para alimentação escolar nos municípios do estado de São Paulo. Contribuindo para confirmar que a agricultura familiar é uma fonte de acesso a alimentos in natura para o PNAE, refletindo em um cardápio escolar mais equilibrado e saudável, com alimentos frescos e locais.

Após a vigência da Lei no 11.947/2009 houve aumento das vendas dos agricultores para os mercados institucionais. E foi possível observar que os fatores que mais dificultam a venda da agricultura familiar para o PNAE são a necessidade de apoios técnico e institucional. Dessa forma, se torna essencial o apoio técnico e institucional direcionado aos pequenos produtores rurais para que consigam atender as demandas do PNAE.

Quando o presente estudo foi realizado, o processo de implementação da lei ainda estava no início em várias cidades. Sugerimos a expansão do estudo para outros estados brasileiros, tendo em vista que as informações de dados sobre o fornecimento de alimentos da agricultura familiar permitem a avaliação desta política de compras do PNAE. Logo, faz-se necessário investigar com mais profundidade indicadores associados à Lei do Programa de Alimentação Escolar brasileiro.

\section{REFERÊNCIAS}

[1] Toyoyoshi JY, Oliveira R, Santos MSN, Galisa MS, Galante AP. Avaliação da aquisição de gêneros alimentícios provenientes da agricultura familiar para a alimentação escolar. Mundo Saúde. 2013; 37(3):329-335.

[2] Triches RM, Schneider S. Alimentação escolar e agricultura familiar: reconectando o consumo à produção. Saude Soc [Internet]. 2010 [acesso em 2019 ago 06]; 19(4):933-945. Disponível em: https://doi.org/10.1590/S0104-12902010000400019.

[3] Ferigollo D, Kirsten VR, Heckler D, Figueredo OAT, Perez-Cassarino J, Triches RM. Aquisição de produtos da agricultura familiar para alimentação escolar em municípios do Rio Grande do Sul. Rev Saúde Pública. 2017;51:56

[4] Saraiva EB, Silva APF, Souza AA, Cerqueira GF, Chagas CMS, Toral N. Panorama da compra de alimentos da agricultura familiar para o Programa Nacional de Alimentação Escolar. Cienc Saude Coletiva [Internet]. 2013 [acesso em 2019 ago 06]; 18(4):927-935. Disponível em: https://doi.org/10.1590/S1413-81232013000400004.

[5] Brasil. FNDE - Fundo Nacional de Desenvolvimento da Educação. Resolução/CD/FNDE no 32, de 10 de agosto de 2006. Estabelece as normas para a execução do Programa Nacional de Alimentação Escolar - PNAE. Brasília: FNDE; 2013.

[6] Brasil. FNDE - Fundo Nacional de Desenvolvimento da Educação. Lei no 11.947 , de 16 de junho de 2009. Dispõe sobre o atendimento da alimentação escolar e do Programa Dinheiro Direto na Escola aos alunos da educação básica. Brasília: Diário Oficial da União. 2009 jun 16.

[7] Azevedo E, Rigon SA. Sistema alimentar com base no conceito de sustentabilidade. In: Taddei JA, Lang RMF, Longo-Silva G, Toloni MHA, organizadores. Nutr Saúde Pública. Rio de Janeiro: Rubio; 2011. p. 543-560.

[8] Burlandy L, Maluf RS. Soberania alimentar. In: Conselho Nacional de Segurança Alimentar e Nutricional. A segurança alimentar e nutricional e o direito humano à alimentação adequada no Brasil: indicadores e monitoramento da 
constituição de 1988 aos dias atuais. Brasilia: CONSEA; 2010. Unidade 1-2.

[9] Belik W, Souza LR. Algumas reflexões sobre os programas de alimentação escolar na América Latina. Planej Polít Públicas. 2009;33:103-122.

[10] Teo CRPA, Monteiro CA. Marco legal do Programa Nacional de Alimentação Escolar: uma releitura para alinhar propósitos e práticas na aquisição de alimentos. Rev Nutr. [Internet]. 2012 [acesso em 2019 mai 23]; 25(5):657-668. Disponível em: https://doi.org/10.1590/S141552732012000500010 .

[11] Carvalho DG. Licitações sustentáveis, alimentação escolar e desenvolvimento regional: uma discussão sobre o poder de compra governamental a favor da sustentabilidade. Plan Polit Publicas. 2009;32:115-147.

[12] Turpin ME. A alimentação escolar como fator de desenvolvimento local por meio do apoio aos agricultores familiares. Segur Aliment Nutr. [Internet]. 2009 [acesso em 2019 set 27]; 16(2):20-42. Disponível em: https://doi.org/10.20396/san.v16i2.8634783

[13] European Commission. Green public procurement: a collection of good practices. Luxembourg: Publications Office of the European Union; 2012.

[14] Chaves LG, Mendes PNR, Brito RR, Botelho RBA. O programa nacional de alimentação escolar como promotor de hábitos alimentares regionais. Rev Nutr [Internet]. 2009 [acesso em 2019 set 27]; 22(6):857-66. Disponível em: https://doi.org/10.1590/S1415-52732009000600007

[15] Sambuichi RHR, Silva AM, Oliveira MAC, Savian M. Compras Públicas sustentáveis e agricultura familiar: a experiência do programa de aquisição de alimentos (PAA) e do programa nacional de alimentação escolar (PNAE). In: Sambuichi RHR, Silva AM, Oliveira MAC, Savian M (Orgs). Políticas agroambientais e sustentabilidade desafios, oportunidades e lições aprendidas. Brasília: IPEA, 2014.

[16] Spinelli MAS, Canesqui AM. O programa de alimentação escolar no estado de Mato Grosso: da centralização à descentralização (1979-1995). Rev Nutr [Internet]. 2002 [acesso em 2019 jun 24]; 15(1):105-117. Disponível em: https://doi.org/10.1590/S1415-52732002000100011.

[17] Santos LMP, Araújo MPN, Martins MC, Veloso IC, Assunção MP, Santos SMC. Avaliação de políticas públicas de segurança alimentar e combate à fome no período 19952002. Cad Saude Publica. [Internet]. 2007 [acesso em 2019 jun
24]; 23(8):1931-1945. Disponível em: https://doi.org/10.1590/S0102-311X2007001100016.

[18] Monteiro CA, Cannon G, Levy RB, Moubarac JC, Jaime PC, Martins AP, et al. NOVA. A estrela brilha. Classificação dos alimentos. Saúde Pública. World Nutrition. 2016;7(13):28-40.

[19] Bicalho D, Villar BS. Efeito da lei do Programa Nacional de Alimentação Escolar na qualidade nutricional dos cardápios escolares. Segur Aliment Nutr. [Internet]. 2019 [acesso em 2020 mar 02]; 26:1-13. Disponível em: https://doi.org/10.20396/san.v26i0.8655583.

[20] Brasil. Guia alimentar para a população brasileira. Ministério da Saúde. Brasília: Ministério da Saúde; 2014.

[21] FNDE - Fundo Nacional de Desenvolvimento da Educação. Resolução/CD/FNDE no 26, de 17 de junho de 2013. Dispõe sobre o atendimento da alimentação escolar aos alunos da educação básica no âmbito do Programa Nacional de Alimentação Escolar - PNAE. Brasília: FNDE; 2013.

[22] Schwartzman F, Mora CAR, Bogus CM, Villar BS. Antecedentes e elementos da vinculação do programa de alimentação escolar do Brasil com a agricultura familiar. Cad. Saúde Pública [Internet]. 2017 [acesso em 2020 mar 02]; 33(12): e00099816. Disponível em: https://doi.org/10.1590/0102-311x00099816.

[23] Oliveira MAC, Sambuichi RHR, Silva APM. Experiências agroecológicas brasileiras: uma análise a luz do desenvolvimento local. Revista Brasileira de Agroecologia. 2013;8(2):14-27.

[24] Dias TF, Nunes EM, Torres FL, Torres ACM. O Programa de Aquisição de Alimentos da Agricultura Familiar (PAA) como estratégia de inserção socioeconômica: o caso do Território da Cidadania Sertão do Apodi (RN). Rev. Bras. de Gestão e Desenvolvimento Regional. 2013;9(3):100-129.

[25] Triches RM, Baccarin JG. Interações entre alimentação escolar e agricultura familiar para o desenvolvimento local. In: Teo CRPA, Triches RM. Alimentação Escolar construindo interfaces entre saúde, educação e desenvolvimento. Chapecó: Ed. Argos; 2016.

[26] Tesche RW, Machado JAD. A importância da reciprocidade no desempenho socioeconômico da agricultura familiar. Rev Estudos do CEPE. 2012;36:7-37.

[27] Costa BAL, Junior PCGA, Silva MG. As Cooperativas da Agricultura Familiar e o Mercado de Compras Governamentais em Minas Gerais. Rev. Econ. Sociol. Rural 
[Internet]. 2015 [acesso em 2019 jun 24]; 53:109-126.

Disponível em: https://doi.org/10.1590/1234-56781806-

9479005301006.

[28] Souza LBB. Organizações da Agricultura Familiar no Estado de São Paulo e sua Experiência de Fornecimento para o PNAE. In: Projeto Nutre SP: análise da inclusão da agricultura familiar na alimentação escolar no estado de São Paulo, São Paulo: Instituto Via Pública; 2012.

[29] Alexandre VP, Gomes LOF, Silva SU, Almeida GM, Martins KA, Monego ET, et al. Do campo à escola: compra de alimentos da agricultura familiar pelo Programa Nacional de Alimentação Escolar em Territórios da Cidadania de Goiás. Segur Aliment Nutr [Internet]. 2016 [acesso em 2019 jun 24]; 23:1049-1064. Disponível em: https://doi.org/10.20396/san.v23i0.8648015.

[30] Corrêa ES, Silva LX, Agne CL. Programa nacional de alimentação escolar: um canal de comercialização da agricultura familiar em São Lourenço do Sul. In: 51으 Congresso da Sociedade Brasileira de Economia, Administração e Sociologia Rural: novas fronteiras da agropecuária no Brasil e na Amazônia - desafios da sustentabilidade, 2013; Belém. Belém: SOBER; 2013.

[31] Alexandre VP, Martins BB, Harold CAS. Construindo novas trajetórias e fortalecendo redes por meio de desenvolvimento rural sustentável - FANUT 133. Relatório final. Goiânia: Universidade Federal de Goiás; 2014.

[32] Triches RM, Schneider S. Desestruturar para construir: interfaces para a agricultura familiar acessar o programa de alimentação escolar. Estudos Sociedade e Agricultura. 2012;20:66-105.

[33] Bevilaqua K, Triches RM. Implicações da venda de gêneros alimentícios ao Programa de Alimentação Escolar nos aspectos de renda e organização dos agricultores familiares. Segur Aliment Nutr [Internet] 2014 [acesso em 2019 set 19]; 21(2):448-460. Disponível em: https://doi.org/10.20396/san.v21i2.8634474.

[34] Gonçalves DB. Os desafios da Agricultura Familiar frente aos Programas de compras públicas de alimentos: um estudo sobre agricultores da região sudoeste do estado de São Paulo. Revista da Universidade Vale do Rio Verde. 2014;12:604-613. 